\section{Edyeasáa

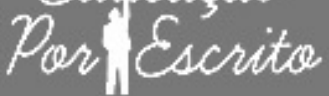

ARTIGO

\section{Editor}

Alexandre Anselmo Guilherme PUCRS, RS, Brasil

\section{Editor Assistente}

Cibele Cheron

PUCRS, RS, Brasi

\section{Editores Associados}

Bruno Antonio Picoli

Universidade Federal da Fronteira Sul, Chapecó, SC, Brasil

Pricila Kohls dos Santos Universidade Católica de Brasília, Brasília, DF, Brasil

Renato de Oliveira Brito

Universidade Católica de Brasilia, Brasilia, DF, Brasil

Elisa Ustarroz

PUCRS, Porto Alegre, RS, Brasil

\section{ISSN 2179-8435}

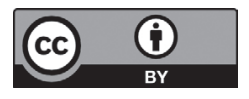

Este artigo está licenciado sob forma de uma licença Creative Commons Atribuição 4.0 Internacional, que permite uso irrestrito, distribuicăo e reprodução em qualquer meio, descorretamente citada.

\title{
"Queremos ser sujeitos do sistema educacional": as implicações do trabalho pedagógico na permanência e êxito de estudantes na Educação Profissional e Tecnológica
}

\author{
"We want to be subjects of the educational system": \\ the implications of pedagogical work in permanence and student success in \\ Vocational and Technological Education \\ Rozieli Bovolini Silveira ${ }^{1}$ \\ Mariglei Severo Maraschin ${ }^{1} 1$ \\ ${ }^{1}$ Universidade Federal de Santa Maria (UFSM), Santa Maria, RS, Brasil.
}

\section{RESUMO}

Esse artigo é resultado de uma pesquisa de mestrado sobre o tema da permanência e o êxito de estudantes na Educação Profissional e Tecnológica. A pesquisa teve como ênfase a análise da política denominada Programa Permanência Êxito (PPE). O objetivo foi compreender as possíveis relações entre o Trabalho Pedagógico e o sucesso ou fracasso escolar e, para isso, partiu de uma concepção crítica da Educação. Para o levantamento de dados foram entrevistados(as) os(as) coordenadores(as) do PPE e dos Eixos Tecnológicos de dois campi do Instituto Federal Farroupilha, além da aplicação de um questionário para os estudantes dos Cursos Técnicos e observações sistematizadas nos Diários de Campo. A partir da produção dos dados foi possível compreender que as relações no Trabalho Pedagógico ocorreram de duas formas: quando o estudante se sente acolhido pela instituição ou quando as relações no Trabalho Pedagógico (TP) reafirmam a exclusão, selecionando os mais "aptos".

Palavras-chave: Programa Permanência e Êxito. Educação Profissional e Tecnológica. Trabalho Pedagógico.

\section{ABSTRACT}

This article is the result of a master's research on the subject of the permanence and success of students in Vocational and Technological Education. The research had as an emphasis the analysis of the policy called Stay Success Program (PPE). The objective was to understand the possible relationships between Pedagogical Work and school success or failure and for this, started from a critical conception of education. As data production, the PPE coordinators and Technological Axes were interviewed at two Campuses of Federal Institute Farroupilha, in 
addition to this, a questionnaire to students of the Technical Courses was applied and systematized observations in the field record book were done. From the data production, it was possible to understand that the relations in the Pedagogical Work occurred in two ways, when the student feels welcomed by the institution or when the relations in the Pedagogical Work reaffirm the exclusion, selecting the most "fit".

Keywords: Permanence and Success Program. Professional and Technological Education. Pedagogical Work.

\section{Introdução}

Essingen sse artigo é parte do resultado da pesquisa de mestrado intitulada "O Programa Permanência e Êxito no Instituto Federal Farroupilha: trabalho pedagógico e fracasso escolar" de autoria da pesquisadora Rozieli B. Silveira e orientação da professora Mariglei Severo Maraschin. As indagações sobre a complexidade da Educação Profissional e Tecnológica, em específico a permanência e êxito de muitos estudantes-trabalhadores, surgiram a partir das vivências dessas como servidoras de instituições que oferecem Educação Profissional e Tecnológica.

A referida pesquisa analisou o desenvolvimento da Política Institucional implementada pelo Programa Permanência e Êxito (PPE) no Instituto Federal Farroupilha, a partir de dois campi desse Instituto. Para isso foram entrevistados os(as) coordenadores(as) do Programa Permanência e Êxito (PPE) e coordenadores(as) de Curso ou de Eixo Tecnológico dos campi pesquisados. Os estudantes dos Cursos Técnicos Integrados ao Ensino Médio e dos Cursos Técnicos Subsequentes também foram convidados a responder um questionário, buscando a percepção deles sobre a Educação ofertada e os fatores para permanência.

A evasão e a retenção de estudantes da Rede Federal de Educação Profissional e Tecnológica foi objeto de auditoria do Tribunal de Contas da União que gerou o Acórdão TCU no 506 de 13 de março de 2013, apontando índices elevados de evasão e retenção na rede, recomendando à Secretaria de Educação Profissional e Tecnológica (SETEC), o desenvolvimento de ações a fim de minimizar esses efeitos. O Acórdão do TCU analisou cinco questões relacionadas aos resultados da Educação Profissional dos Institutos Federais e uma delas foi a caracterização da evasão escolar, apresentando, ainda, apontamentos de como reduzi-la.

A atenção do TCU é em virtude da grande expansão da Rede Federal a partir de 2008 e, consequentemente, dos altos investimentos financeiros dos cofres públicos. Os índices apontados pelo TCU ${ }^{1}$ indicam a taxa de evasão nos

1 Índices de 2013 na Rede Federal de Educação Profissional e Tecnológica. 
Cursos Técnicos Integrados ao Ensino Médio de 6,4\% e de retenção de 44,4\%. Já nos Cursos Técnicos Subsequentes, o índice de evasão foi de $18,9 \%$ e de retenção $49,3 \%$. Um diagnóstico qualitativo e quantitativo ${ }^{2}$ também foi realizado no IF Farroupilha e revelou que em 2014 o índice de evasão nos cursos integrados, em uma média de todos os campi, foi de 10,3\%, e nos Cursos Subsequentes, 19,2\%. Os índices de retenção na Instituição são ainda maiores, $69,2 \%$ nos Cursos Subsequentes e $19,1 \%$ nos cursos integrados.

Os dados apontam para a realidade dos estudantes que acessam aos cursos técnicos, mas que não têm garantias sobre a permanência e o êxito. Para isso é necessário o entrelaçamento de políticas educacionais e a ressignificação dos sujeitos em relação a essas políticas, para que assim, os estudantes acessem a Educação como um direito fundamental.

Assim, essa pesquisa tem como objetivo compreender as possíveis relações entre o Trabalho Pedagógico e o sucesso ou fracasso escolar e para isso parte de uma concepção crítica da Educação, da qual busca desvelar os fatos que determinam a vida das pessoas, nesse caso, dos estudantes que acessam os Institutos Federais de Educação, Ciência e Tecnologia. Por isso a perspectiva crítica vai ao encontro da proposta desse trabalho: olhar e sentir o real a partir de um lugar de trabalhadora que a pesquisadora ocupa, nas suas contradições, com os movimentos históricos que constituem a vida em sociedade. Descendo ao concreto serão apresentadas as relações no Trabalho Pedagógico e a permanência e o êxito dos estudantes no Instituto Federal Farroupilha.

\section{A categoria Trabalho Pedagógico e as relações com os sujeitos estudantes}

A relação trabalho e educação é experienciada pelos sujeitos que vivem as políticas sociais e educacionais na escola, no cotidiano das contradições, na educação escolar fragmentada, no mundo do trabalho. A tensão dessa relação é sentida, vivenciada e produzida e como Arroyo (2012) destaca: “Toda educação acontece entre sujeitos. É construtivo de toda prática educativa e cultural ser uma ação humana, de sujeitos humanos, daí estar sempre marcada pela diversidade de experiências culturais dos sujeitos que delam participam" (ARROYO, 2012, p. 165). Essa direção aponta para uma relação trabalho-educação com criadores da vida individual e social que é materializada e vivida na contradição, pelos sujeitos da escola, a partir da práxis do Trabalho Pedagógico.

A categoria do Trabalho Pedagógico é desenvolvida pelo Grupo de Estudos e Pesquisa Kairós da Universidade Federal de Santa Maria (UFSM) e pelo Grupo de Estudos e Pesquisa Trabalho Pedagógico e Políticas Educacionais

\footnotetext{
2 Diagnóstico quantitativo realizado a partir dos dados extraídos do Sistema Nacional de Informações da Educação Profissional e Tecnológica - SISTEC. O diagnóstico apontará inconsistência nos índices extraídos pelo SISTEC, ou seja, pode não representar uma rigorosa descrição da realidade da instituição.
} 
na Educação Profissional e Tecnológica e a partir das reflexões e discussões iniciadas nos grupos, buscou-se encontrar elementos na pesquisa e na própria categoria que fizessem sentido para explicar a realidade material dos estudantes, professores e técnico-administrativos.

Ferreira (2010) ao explicar a categoria do Trabalho Pedagógico (TP) salienta:

Trabalho pedagógico é a produção do conhecimento, mediante crenças e aportes teórico-metodológicos escolhidos pelos sujeitos, que acontece em contextos sociais e políticos os quais contribuem direta ou indiretamente. Diretamente, porque perpassam o trabalho pedagógico. Indiretamente, quando não são explícitos, todavia, todo trabalho pedagógico é intencional, político e, de algum modo, revela as relações de poderes que nele interferem (FERREIRA, 2010, p.2, grifo nosso).

Ferreira (2010) ainda salienta que os métodos utilizados buscam realizar um objetivo maior: a produção do conhecimento, para o desenvolvimento humano. Isso se dá a partir das relações que se estabelecem entre professores e estudantes, técnico-administrativos e estudantes e estudantes e a própria instituição. Prioritariamente, o Trabalho Pedagógico acontece entre professor e estudante, porém pode ser desenvolvido por outros sujeitos pertencentes à instituição e que representem o projeto pedagógico institucional.

Frizzo, Ribas e Ferreira (2013) justamente reforçam as relações possíveis daqueles que realizam o TP, definindo como as "relações e processos que se estabelecem entre os sujeitos da escola, professores e estudantes, e o conhecimento apreendido por estes durante a vida escolar" (2013, p.554). O TP acontece para que o objetivo da produção do conhecimento seja alcançado e se ofereça aos sujeitos a possibilidade de desenvolvimento político, ético e humano.

Sobre o Pedagógico e a produção do conhecimento, Ferreira (2017), em Trabalho Pedagógico na escola: sujeitos, tempo e conhecimentos, esclarece:

Pedagógico é todo o pensar-agir da escola com o intuito de produzir conhecimento. Porém, não é pedagógico o pensar-agir, embora muito bem organizado, incoerente com a expectativa de produção do conhecimento dos sujeitos da aula. Percebe-se, então, não haver como dissociar uma concepção do pedagógico do espaço, do tempo e do trabalho realizado na escola. Pedagógico é a articulação desses fatores, objetivando a produção do conhecimento. Afinal, se os sujeitos-estudantes ingressam na escola é porque intencionam aprender. E aprender é um complexo movimento de linguagens em interlocução, subjetividades em interação e historicidades que se entrelaçam objetivando ampliar as compreensões de mundo, inserir-se cada vez mais na cultura e "genteificar-se" (em referência a toda obra de Paulo Freire), ainda mais (FERREIRA, 2017, p. 117). 
As relações estabelecidas pelos sujeitos são as condições para que aconteça a produção do conhecimento e, assim, o Trabalho Pedagógico. Esse objetivo maior - a produção do conhecimento - é cercado de intenções e por isso não é neutro. Mesmo que essas intenções sejam inconscientes, as relações estabelecidas demarcaram como o TP será realizado (FERREIRA, 2010). Essencialmente o TP acontece a partir das relações, pois "exige interação com outros sujeitos, possibilidade de linguagens em interlocução e conciliação entre a proposta e um referencial teóricometodológico" (FERREIRA, 2010, p. 1).

Saviani, (2011) no livro Pedagogia Histórico-Crítica: primeiras aproximações também descreve as relações entre trabalho e educação.

Para sobreviver, o homem necessita extrair da natureza, ativa e intencionalmente, os meios de sua subsistência. Ao fazer isso, ele inicia o processo de transformação da natureza, criando um mundo humano (o mundo da cultura). Dizer, pois, que a educação é um fenômeno próprio dos seres humanos significa afirmar que ela é, ao mesmo tempo, uma exigência do e para o processo do trabalho, bem como é, ela própria, um processo de trabalho (SAVIANI, 2011, p. 11).

O humano torna-se humano pelo processo do trabalho, como "característica essencialmente humana, como o que identifica o homem e o diferencia do restante da natureza" (PARO, 2000, p. 29). E é por isso, pelo trabalho, que é possível considerarmos o ser humano como histórico e social. É aqui que a relação trabalho e educação se concretiza, ou seja, é pelo trabalho e pela educação que o humano se torna humano. Um ser ativo, social e histórico.

Paro (2000) ressalva que a aula não pode ser considerada como produto, mas sim o próprio Trabalho Pedagógico. O autor vai ainda mais longe, considerando o TP para além do ato de aprender, pois o educando não está somente na posição de aprendente/consumidor. O estudante aqui é sujeito de trabalho, pois é sobre ele que se processa o Trabalho Pedagógico e que se transforma a partir dele e para além dele.

[...] a resposta do educando nesse processo se dá de acordo com a sua especificidade humana, que é ao mesmo tempo natural e transcendência do natural. É, pois, uma participação ativa, enquanto ser histórico. Em vista disso, o papel do educando no processo de produção pedagógico se dá não apenas na condição de consumidor e de objeto de trabalho mas também na de sujeito, portanto de produtor (ou coprodutor) em tal atividade (PARO, 2000, p. 32, grifo do autor e grifo nosso).

Seria então o TP o condutor que proporciona ao estudante a transformação, pois necessariamente ele sai diferente do que entrou. A possibilidade de transformação foi encontrada nas visitas aos campi do Instituto. No final do ano 
de 2016, período de levantamento de dados foi possível perceber a mobilização com as ocupações das Instituições. As ocupações denunciavam e faziam resistência às propostas de grandes cortes na educação, materializadas na PEC 55 (Figura 1).

Figura 1 - Fotografia do cartaz no Campi 2

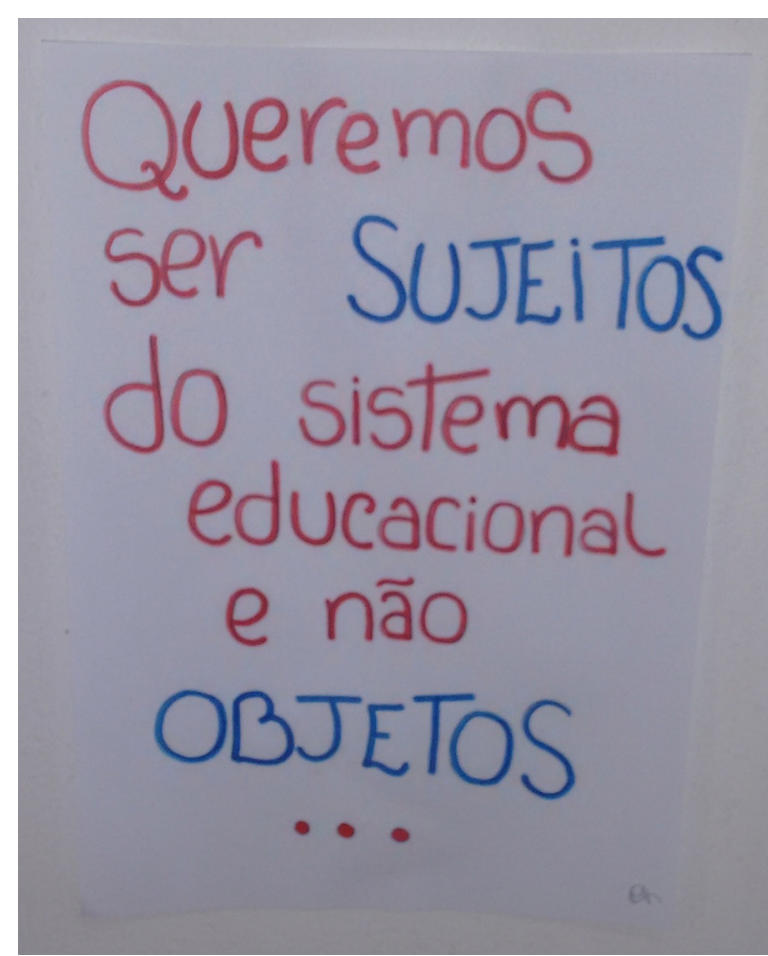

Fonte: Arquivo pessoal das autoras

Ainda no relato produzido através do Diário de Campo, sobre os aspectos físicos do ambiente, é destacada a organização dos "cartazes sobre a ocupação, como defesa da educação pública, contra o machismo, a opressão, o racismo" (Diário de Campo 21/11/16). E, ainda, sobre a integração dos estudantes: 
"Quando cheguei ao campus, percebi que o movimento das ocupações fazia uma importante ação de integração. No refeitório os estudantes debatiam sobre as ocupações, em um dos prédios os estudantes estavam sentados, tocando violão. Ao lado estavam os colchões empilhados e roupas de cama, demonstrando o espaço físico do qual estavam ocupando. Quando adentrei nesse prédio, os estudantes solicitaram o meu nome e para onde eu ia. Disse meu nome e qual o meu objetivo. Conversamos brevemente e pude entrar e sair do prédio." (Pesquisadora, informação verbal) ${ }^{3}$

Nesse pequeno relato é possível perceber os movimentos de resistência, de integração, de transformação, sinalizando mais uma vez o que Paro (2000, p.33) afirmou: "se o processo de trabalho pedagógico se realizou a contento, consideramos que o educando que "sai" do processo é diferente daquele que aí entrou". Esse processo é construído dialeticamente, em uma contínua negociação de sentidos.

Porém é preciso lembrar que muitas vezes essa saída é precoce, denominada evasão. E assim questiona-se: O TP é subordinado ao capital? Quais as contradições que revelam essas relações? É possível ser sujeito no sistema educacional alicerçado no capitalismo?

Partindo da relação do trabalho e da educação como próprio do humano até as contradições que a escola capitalista duramente impõe aos sujeitos da escola, Frizzo Ribas e Ferreira (2013) farão uma análise sobre essas contradições que se expressam na escola capitalista. Para os autores é possível afirmar que o disciplinamento e a empregabilidade são duas categorias que organizarão o TP na escola capitalista. Sobre essa relação entre sujeito e objeto Frizzo, Ribas e Ferreira (2013) avaliam.

O capital contribui para intensificar a exploração da força de trabalho, através da lógica da formação profissional em detrimento da formação humana, por exemplo. Esse é o imperativo que tem organizado o modo como a escola capitalista tem se estruturado, contribuindo para transformar os sujeitos do trabalho pedagógico em objetos, ao reduzir a produção do conhecimento escolar em produção da mercadoria força de trabalho (FRIZZO; RIBAS; FERREIRA, 2013, p. 558).

Nesse sentido que o TP assume duas possibilidades, uma relacionada ao fazer do estudante objeto, e outra, sujeito. O TP organizado conforme a escola capitalista, ou seja, que preze pelo disciplinamento e a empregabilidade (FRIZZO; RIBAS; FERREIRA, 2013) terá como resultado e processo a evasão e a retenção. A lógica de que os

3 Depoimento da pesquisadora registrado no Diário de Campo, no Campus 2 do IF Farroupilha, no dia 21 de novembro de 2016. Os campi pesquisados foram identificados como Campus 1 e Campus 2. 
"melhores vencem" estará perfeitamente condizente com a escola capitalista. Nesse caso, os estudantes, evadidos e repetentes são os que não foram suficientemente disciplinarizados e nem considerados os melhores.

O disciplinamento é sentido por todos que se inserem na linha de montagem educacional, tanto pelo estudante como pelo próprio professor. A finalidade do TP, nessas condições, é a empregabilidade, a vida produtiva e social ditados pelo capitalismo (FRIZZO; RIBAS; FERREIRA, 2013). Assim "o tempo de aprendizagem não tem valor por si mesmo, tornando-se preparação para a 'verdadeira vida', ou seja, o trabalho capitalista fora da escola [...]" (FRIZZO; RIBAS; FERREIRA, 2013, p. 561).

"Os sentidos que a educação ofertada pelo Instituto Federal têm para os estudantes participantes da pesquisa, vai ao encontro da concepção 'preparação para a vida'. Essa questão é observada nos questionários aplicados aos estudantes, com a pergunta sobre quais eram os fatores para continuar estudando no IF Farroupilha. Algumas respostas como: 'Gosto do curso e tenho expectativas para o futuro nessa área', 'no futuro ter um emprego melhor e que ganhe mais', 'o IF Farroupilha tem um ótimo ensino, pois os alunos já saem treinando para o trabalho e os professores são bem qualificados', 'para melhor facilitar minha vida e poder me preparar para o futuro', 'aprimorar conhecimento, para ter um futuro brilhante', 'buscar conhecimento, para chegar preparado no mercado de trabalho', 'garantir meu futuro', 'conhecimento, assim proporcionando um futuro melhor, com maiores chances de ingresso na área de trabalho', 'preciso estudar para no futuro conseguir uma melhor carreira profissional', 'meu futuro'." (Informação escrita) ${ }^{4}$

É possível perceber que o disciplinamento foi necessário para que o futuro, leia-se, empregabilidade, seja mais possível. Essa é a concepção dos jovens estudantes dos cursos técnicos sobre a educação ofertada e os motivos que fazem deles permanecer na Instituição. A relação entre Educação e trabalho é separada, ora para o estudo, ora para o futuro, trabalhar. Frizzo, Ribas e Ferreira (2013) retomam que as intencionalidades da escola estão alicerçadas na perspectiva do vir a ser, na ideia de que a educação hoje servirá para a possibilidade do trabalho amanhã. A fragmentação da educação e do trabalho está posta e, assim, "esses aspectos do disciplinamento se definem como estruturantes de uma subjetividade que interessa aos mecanismos de exploração e aceitação impostos pelo modelo de produção atual" (FRIZZO; RIBAS; FERREIRA, 2013, p. 561).

Tanto o disciplinamento, quanto a empregabilidade fazem parte da organização do TP subordinado ao capital. E esse disciplinamento será necessário para que se concretize a empregabilidade e não para o emprego ou trabalho,

4 São respostas escritas pelos estudantes dos cursos integrados ao ensino médio e subsequentes em uma das perguntas abertas do questionário. A aplicação do instrumento de pesquisa se deu no período de novembro a dezembro de 2016. 
apenas uma expectativa para tal. Como o objetivo de desenvolver "capacidade flexível de adaptação individual às demandas do mercado" (FRIZZO; RIBAS; FERREIRA, 2013, p. 562).

Kuenzer (2002) no artigo que aborda a Exclusão Includente e a Inclusão Excludente, retomando as propostas da pedagogia toyotista e da pedagogia socialista, analisa o quanto o trabalho pedagógico reproduz as contradições presentes no capitalismo, visto que reafirma o disciplinamento na vida educacional, social e produtiva. Especialmente, a formação oferecida aos estudantes, que está diretamente relacionada às necessidades e valorização do capital. Sobre o TP, Kuenzer (2002) afirma:

[...] em uma sociedade dividida em classes, onde as relações sociais são de exploração, ele desempenhará a função de desenvolver subjetividades tais como são demandadas pelo projeto hegemônico, neste caso, o do capital. Neste sentido, pode-se afirmar que a finalidade do trabalho pedagógico, articulado ao processo de trabalho capitalista, é o disciplinamento para a vida social e produtiva, em conformidade com as especificidades que os processos de produção, em decorrência do desenvolvimento das forças produtivas, vão assumindo (KUENZER, 2002, p. 5, grifo nosso).

Mas ainda se questiona além: seria possível um TP que favorecesse a condição humana, em uma perspectiva crítica da Educação?

Na Tese de Doutorado de Maraschin (2015) a autora elabora duas concepções sobre o Trabalho Pedagógico. Uma delas é o TP Ingênuo e outra, o TP crítico. O TP ingênuo é aquele baseado em uma concepção alienada, de uma Pedagogia que compreende que o conhecimento é transmitido do professor ao aluno. Inversamente, o TP crítico é aquele que permite que estudantes e professores construam dialeticamente a educação, conscientes do espaço que ocupam, histórico e socialmente.

Maraschin (2015, p. 59) defende que a concepção crítica do TP é aquela em que esse "se adapta as condições dos estudantes, às suas imediatas possibilidades de ascensão cultural”. Ou seja, é possível que o TP favoreça a condição de humano, que permita ver a educação em uma perspectiva para além do disciplinamento e da empregabilidade. Permite ainda, compreender os sujeitos dessa relação, a partir da sua história, do espaço concreto que ocupam na sociedade, das suas condições de vida. A autora acrescenta:

Sendo que no trabalho pedagógico ingênuo, o estudante é visto como "ignorante" em sentido absoluto, como "objeto" da educação, a educação é concebida como transferência de um conhecimento finito e como dever moral da fração adulta, educada e dirigente da sociedade. [...] Já no trabalho pedagógico crítico, o estudante é visto como sabedor e desconhecedor, é "sujeito" da educação e a educação consiste em uma nova proporção entre conhecimento e desenvolvimento (MARASCHIN, 2015, p. 258-259). 
Retomando o cartaz colado na parede de um dos campi pesquisado, a voz desses estudantes é expressa: "queremos ser sujeitos do sistema educacional e não objetos". O TP desejado por esses é também por um TP crítico (MARASCHIN, 2015), que a produção do conhecimento leve ao desenvolvimento de todos os sujeitos que dele participam (FERREIRA, 2017).

É a partir da construção coletiva do TP que é possível observar na prática, como as políticas educacionais, nesse caso, a política de Educação Profissional e Tecnológica, vão adquirindo concretude. É possível que os vínculos que se estabelecem entre os sujeitos da escola possam diminuir os índices de evasão, pois seria possível o entendimento do processo educativo em uma perspectiva histórica e crítica da sociedade (MARASCHIN, 2015).

Assim entendendo o TP, o elemento relacional que permite a produção do conhecimento e o desenvolvimento humano, ético e político, propõe-se refletir as relações possíveis entre o TP realizado pelos professores e equipe pedagógica dos campi e a permanência, o êxito e o fracasso dos estudantes.

\section{O Trabalho Pedagógico e permanência e êxito dos estudantes}

Aqui é discutido o Trabalho Pedagógico enquanto possibilitador ou não da permanência e êxito dos estudantes. Parte-se de que o Trabalho Pedagógico é essencialmente conduzido por pessoas, e que a partir dessa relação, dessa interlocução (FERREIRA, 2010) que será possível a produção do conhecimento, como já discutido anteriormente. Com base nisso é que se discute o TP essencialmente realizado por sujeitos e que dessas relações sociais, a possibilidade da permanência e êxito.

É pelo trabalho que o ser humano estabelece relações com a natureza e assim com os outros homens, assim "o trabalho só pode ser entendido dentro de relações sociais determinadas. [...] Por isso, quando se diz que o ser humano é ativo, diz-se, ao mesmo tempo, que ele é um ser social" (BOCK; FURTADO; TEIXEIRA, 2010, p. 79). Sobre as relações sociais e a constituição dos sujeitos, os autores acrescentam:

As relações sociais têm enorme importância para a teoria. Os vínculos que se constituem vão permitir determinadas experiências. Em nossas vivências somos afetados (de afetividade) de alguma forma e fazemos então nossos registros emocionados. O mundo psicológico como um mundo de símbolos, imagens, sensações e emoções vai se organizando em nós e permitindo a formação da consciência. A linguagem, com suas palavras, é um dos mais importantes veículos de transporte do campo objetivo para o campo da subjetividade e vice-versa (BOCK; FURTADO; TEIXEIRA, 2010, p. 81, grifo nosso). 
Ou seja, não é mais possível explicar a realidade pela dicotomia entre mundo interno versus mundo externo ou social versus individual (BOCK; GONÇALVES; FURTADO, 2015). Os processos, que definem o humano enquanto humano, acontecem conjuntamente e, por isso, a indagação sobre o TP e as relações sociais.

Pensar as relações sociais é pensar os sujeitos que experimentam a realidade concreta e dela produzem sentidos e, assim, mudam a si mesmos e o mundo, e são mudados pelo mundo também (BOCK; FURTADO; TEIXEIRA, 2010). É a partir dessa realidade concreta que o "sujeito atua, vivencia relações, estabelece vínculos, convive com significados, experimenta emoções e produz sentidos" (BOCK; FURTADO; TEIXEIRA, 2010, p. 82). Miguel Arroyo (2012) reforça que toda educação se dá pela ação humana, ação essa que pode ser entre pessoas, de pessoas sobre outras e, por isso, a necessidade do elemento humano ser o centro das pesquisas de Educação e trabalho.

Sem dúvida será importante pesquisarmos a organização do trabalho, as novas tecnologias, os rituais, tempos e espaços, os regimentos, as grades curriculares, tudo o que objetiva e concretiza a pedagogia da fábrica ou da escola, entretanto, o central em nossas pesquisas terão que ser os sujeitos que interferem nessa relação educativa. A teoria pedagógica e a relação trabalho-educação se empobrecem quando seu foco deixa de ser as pessoas, as relações sociais e a passam a privilegiar as técnicas, as tecnologias, os métodos, os conteúdos inculcados (ARROYO, 2012, p. 165).

Dessa forma as relações sociais no Trabalho Pedagógico foram analisadas a partir do discurso dos sujeitos que vivem as políticas educacionais. Então, a compreensão dessa categoria se deu a partir de outras perguntas, porque se acredita que é possível desvendar elementos mais condizentes com a realidade. Por isso, destaca-se o discurso de um professor e coordenador do PPE no Campus 1.

"O trabalho realizado entre eles de dizer o porquê de se estar aqui, o que se pretende, para que serve a escola... Eles tiveram uma consciência muito boa. E claro, cada um dentro das suas particularidades e individualidades. A partir disso, sentimos uma melhora. Inclusive no relacionamento entre eles, entre os professores, até mesmo pela experiência que eu tenho, nove anos dentro do campus. Deve ter sido um dos primeiros anos que tivemos menos problemas em relação às normas, à disciplina. Isso já é um passo, não é?" (Informação verbal) ${ }^{5}$

\footnotetext{
5 Depoimento do Coordenador do PPE concedido à pesquisadora Rozieli B. Silveira durante as entrevistas, no campus 1 do IF Farroupilha, no dia 10 de novembro de 2016. Não serão identificados os nomes dos coordenadores do PPE e dos cursos, mas apenas seus cargos e o campus no qual trabalham: 1 ou 2 .
} 
A relação é baseada em um vínculo disciplinar, ou seja, a reflexão sobre o pertencimento à instituição tinha como objetivo minimizar a discordância, a desobediência dos estudantes. Em outro relato, o vínculo baseado na disciplina é também referido quando questionado sobre a educação ofertada pelo Instituto Federal.

"Relatos como o agitamento dos estudantes, 'perderam o controle' dos primeiros anos, 'estão na mesma [palavra de baixo calão]', 'é o pior ano de todos os tempos' e como conclusão 'é sempre esse contexto'.” (Informação verbal) ${ }^{6}$

No próximo relato é retomada a questão da disciplina e das notas, além de salientar o apoio que o IF oferece.

"Eu digo para eles quando eles entram no instituto que a única preocupação deles deve ser o estudo. Porque o resto o instituto está apoiando por trás. Como a gente diz, não sabemos onde vai parar a educação, mas que eles aproveitem. Não sabemos quanto tempo teremos, mas que a oportunidade que eles têm, é única. Eu não me lembro de ter tido uma oportunidade dessas, então avalio como muito boa. Há muitas ações pedagógicas, muitos conselhos, trabalho com professores, se está com dificuldade específica na disciplina, é providenciado para abrir monitoria. Então, acho que esse cuidado com relação ao aluno, a disciplina, as notas, eu não vejo igual em outra instituição." (Informação verbal $)^{7}$

O apoio oferecido pelo IF é desenvolvido pela equipe multiprofissional, composta por psicólogos, assistentes sociais, médicos, enfermeiros, dentistas, técnicos de enfermagem, que retomam a importância do cuidado com a saúde do estudante de forma completa. Ou seja, além da cura de possíveis doenças, as equipes multiprofissionais nos IFs têm como propósito a prevenção e a promoção da saúde para assegurar a permanência do estudante (IF FARROUPILHA, 2012). A Política da Assistência Estudantil do IF Farroupilha tem como primeiro objetivo a promoção do "acesso e a permanência na perspectiva da inclusão social e democratização do ensino" (2012, p. 3), desenvolvida conjuntamente com os outros setores pedagógicos do campus.

No relato, o encaminhamento e o monitoramento são elencados como positivos por um dos sujeitos participantes da pesquisa quando questionado sobre a realização do Trabalho Pedagógico.

${ }^{6}$ Depoimento dos integrantes da comissão do PPE concedido à pesquisadora Rozieli B. Silveira durante uma reunião da comissão, no campus 1 do IF Farroupilha, no dia 24 de novembro de 2016.

7 Depoimento do Coordenador de Eixo Tecnológico concedido à pesquisadora Rozieli B. Silveira durante as entrevistas, no campus 1 do IF Farroupilha, no dia 20 de novembro de 2016 
"Eu acho que é muito bom. Pelo aparato que eles têm. Eles têm tudo. Se estiverem com dificuldade, o professor informa. Se estiverem infrequentes, o professor igualmente informa. A vida desses estudantes, penso eu, é monitorada aqui no ensino médio. E realmente é. Se informamos o CAE, a [assistente social] já entra em contato direto com as famílias. Se for problema de nota, cai na DE, na assessoria pedagógica. E como eu te disse, eu não vejo em outra instituição, o aparato que eles têm aqui dentro. Em breve eles terão a odontologia, a enfermeira, eles têm a médica." (Informação verbal) ${ }^{8}$

O encaminhamento também é mencionado durante a entrevista com dois coordenadores de eixo.

"Esses professores tiveram dificuldade de falar sobre o seu trabalho pedagógico, pois no momento que eu questiono sobre o TP eles se entreolham esperando que o outro fale. Um dos professores relatou que as metodologias e avaliações são acordadas no colegiado e que eles, os professores, procuram seguir mais ou menos essa definição. E que os estudantes são encaminhados para o apoio pedagógico quando existem dificuldades." (Informação verbal) ${ }^{9}$

O encaminhamento do estudante pode assumir duas possibilidades, uma delas vinculada a de atuar na perspectiva da equipe multidisciplinar, porém nos relatos dos entrevistados o que ocorre é uma epidemia de encaminhamentos. Machado (1997) no artigo "Avaliação e fracasso: a produção coletiva da queixa escolar" retoma os numerosos encaminhamentos de estudantes para tratamento com diversos profissionais da saúde. Esse mecanismo acaba por reforçar a responsabilização individual sobre o fracasso escolar, ou seja, ao realizar muitos encaminhamentos reforça-se a ideia socialmente construída, de que o problema é do estudante e, por isso, há a necessidade de encaminhar a outros profissionais.

A partir desses discursos é possível perceber a contradição em relação ao Programa Permanência e Êxito e a própria política educacional dos Institutos Federais. As relações que se dão no Trabalho Pedagógico, nesses campi, são relações e vínculos baseados no disciplinamento, no autoritarismo e no encaminhamento. Em um dos relatos de observação de uma reunião sobre o PPE, um dos coordenadores pergunta: “a instituição chama pai e não tem como

8 Depoimento do Coordenador de Eixo Tecnológico concedido à pesquisadora Rozieli B. Silveira durante as entrevistas, no campus 1 do IF Farroupilha, no dia 20 de novembro de 2016.

9 Relato escrito da entrevista com dois Coordenadores de Eixo Tecnológico concedido à pesquisadora Rozieli B. Silveira, no campus 2 do IF Farroupilha, no dia 21 de novembro de 2016. 
ser expulso por três dias?" (Informação verbal). ${ }^{10}$ Esse relato deixa claro o movimento de expulsão e negação para com o estudante, indo de encontro, também, com a política educacional dos IFs.

Ao contrário do que se possa pensar, é a partir desses movimentos de rebeldia, de conflitos, que será possível a transformação, como argumenta Patto (2016): "a convivência de mecanismos de neutralização dos conflitos com manifestações de insatisfação e rebeldia faz da escola um lugar propício à passagem do compromisso humanogenérico" (2016, p. 363). Ou seja, a rebeldia e a contradição são inerentes às escolas e é a partir disso: do movimento de submissão e rebeldia de todos os sujeitos da instituição, a possibilidade de transformação.

Sobre o encaminhamento, ele até pode ser visto como positivo, pois existe uma equipe especializada para diferentes atendimentos, porém parece muito mais como corriqueiro, do que como esporádico. Ainda sobre os encaminhamentos, a relação afetiva mais próxima com o professor foi apontada por uma das servidoras do apoio pedagógico.

"Um integrante do CAE, que participa da reunião, afirma que o 'compromisso primeiro com o aluno é o professor e não encaminhar'. O professor deve 'identificar os alunos que minam os demais'. Outra TAE salienta a importância do vínculo com o professor, do bom relacionamento com o professor, pois vários alunos procuram os professores. A preocupação é com o aluno que está ali." (Informação verbal) ${ }^{11}$

No questionário realizado com os estudantes dos Cursos Integrados e Subsequentes, quando perguntados se já necessitaram de algum tipo de acompanhamento e, se "sim", "qual foi", 21 responderam que "não" e 45 disseram que "sim". Dentre esses que responderam "sim", 33 fizeram relação com o atendimento com psicólogo ou outro profissional da Coordenação da Assistência Estudantil ou Setor de Apoio Pedagógico. Também foram citados o Núcleo de Atendimento de Pessoas com Deficiência e o Núcleo de Estudos Afro-brasileiros e Indígenas. O restante que respondeu "sim" apontou as aulas extras, reforços e recuperações paralelas. Ou seja, um número elevado de estudantes foi encaminhado para algum tipo de acompanhamento, seja psicológico ou pedagógico.

Sobre o relacionamento com os colegas e professores, os estudantes marcaram as opções entre "totalmente satisfeito", "satisfeito", "parcialmente" "satisfeito/insatisfeito", "totalmente insatisfeito", conforme o Gráfico 1 e Gráfico 2.

\footnotetext{
${ }^{10}$ Depoimento dos integrantes da comissão do PPE concedido à pesquisadora Rozieli B. Silveira durante uma reunião da comissão, no campus 1 do IF Farroupilha, no dia 24 de novembro de 2016.

${ }^{11}$ Depoimento dos integrantes da comissão do PPE concedido à pesquisadora Rozieli B. Silveira durante uma reunião da comissão, no campus 1 do IF Farroupilha, no dia 24 de novembro de 2016.
} 
Gráfico 1 - Relacionamento dos estudantes com os próprios colegas

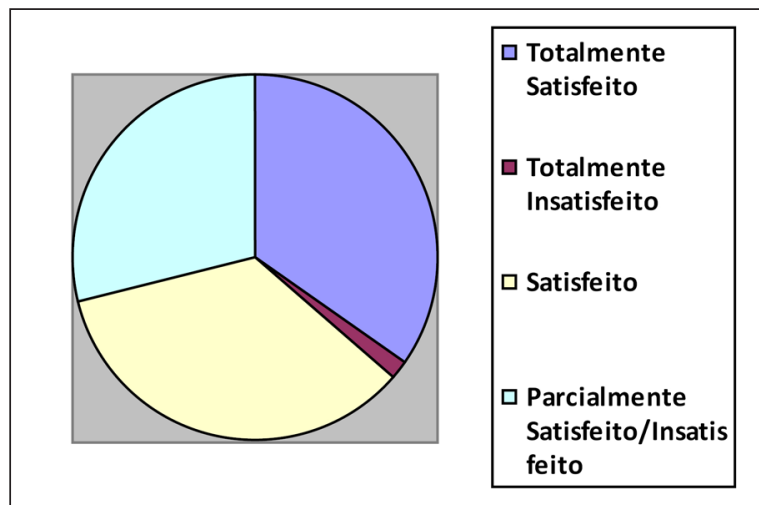

Fonte: Elaborado pelas autoras com base na pesquisa.
Gráfico 2 - Relacionamento dos estudantes com os professores

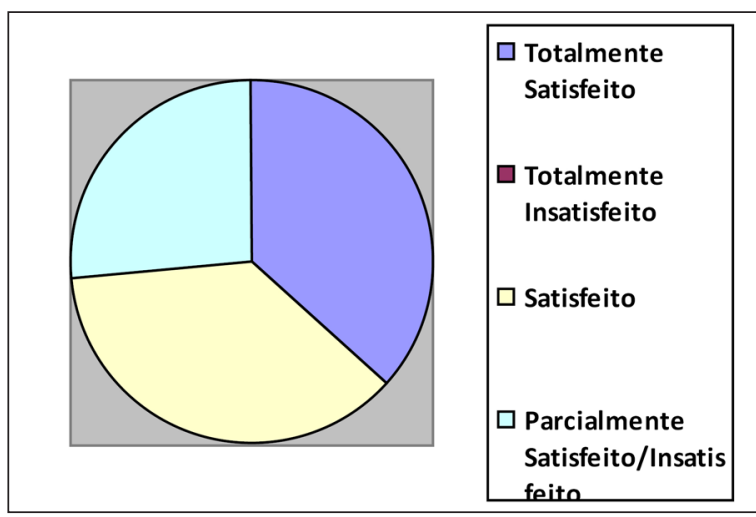

Fonte: Elaborado pelas autoras com base na pesquisa

A partir da discordância entre o discurso dos coordenadores e as respostas dos questionários com os estudantes, questiona-se: como o distanciamento ou aproximação nessas relações entre trabalhadores da escola e estudante, especialmente, estudante e professor, tem relação com o conhecimento a ser produzido? Essas relações são enunciadoras de fracasso escolar ou de permanência e êxito?

Como problematização serão apresentados outros relatos.

"Mas onde temos uma maior dificuldade, ainda tem, efetivamente, mas minimizou bastante, é nos primeiros anos, então planejamos essa acolhida. Por que eles se sentiam, assim... vinham de municípios do interior, de uma escola pequena, onde tinham bastante contato com o professor e chegando aqui eles tinham aquele choque de realidade. Então essa foi uma pauta que foi e está sendo trabalhada com todos os anos, é uma proposta, é uma ação do programa." (Informação verbal) ${ }^{12}$

\footnotetext{
${ }^{12}$ Depoimento do Coordenador do PPE concedido à pesquisadora Rozieli B. Silveira durante as entrevistas, no campus 2 do IF Farroupilha,
} no dia 10 de novembro de 2016. 
"Os alunos e os pais começaram a nos procurar com mais frequência, a dizer coisas que não sabíamos e obviamente o professor que está em sala de aula, com 35 alunos, fica impossibilitado, muitas vezes, pela própria questão da aula, não tem como o professor fazer aquela visão de um único aluno." (Informação



"Dificuldade de adaptação em uma nova escola, com média 7 e com diversos professores, 15 disciplinas; Dificuldade de acompanhar o ritmo da escola." (Informação verbal) ${ }^{14}$

Ou seja, tanto para o professor, quanto para o estudante essas relações tornam-se mais distantes, uma das razões é o grande número de estudantes por professor em sala de aula. Por esses relatos é possível analisar que o Trabalho Pedagógico realizado, nesses campi ainda é baseado em um vínculo que mantém a fragmentação do currículo e o distanciamento entre os sujeitos, que anunciam os riscos para o fracasso escolar, porém há um movimento da instituição para a acolhida aos estudantes e suas famílias, principalmente nos primeiros anos dos cursos integrados. A questão do acolhimento já foi problematizada na pesquisa de mestrado de Guimarães (2012) que aponta essa ação como desencadeadora de uma relação transferencial, explicada pela psicanálise, entre estudante e professor. Segundo a pesquisa estaria nesse acolhimento ${ }^{15}$ inicial, a maior possibilidade de permanência e êxito do estudante. Assim, as relações acolhedoras no TP, que realmente proporcionam uma aproximação singularizada, podem ser o diferencial para a permanência e o êxito do estudante.

$\mathrm{O}$ discurso de um coordenador quando questionado sobre o desenvolvimento do Trabalho Pedagógico está relacionado "às ferramentas pedagógicas”.

“O trabalho pedagógico ele [interrupção]. Acho que o trabalho pedagógico ele é importante no momento que tu começas a dar aula e percebe se a própria metodologia está funcionando, se os alunos estão percebendo. Então a nossa principal etapa pedagógica é acompanhar a ministração da aula e se a metodologia funciona. Se não funciona, para e muda de estratégia.” (Informação verbal) ${ }^{16}$

\footnotetext{
${ }^{13}$ Depoimento do Coordenador do PPE concedido à pesquisadora Rozieli B. Silveira durante as entrevistas, no campus 1 do IF Farroupilha, no dia 10 de novembro de 2016.

${ }^{14}$ Depoimento do Coordenador de Eixo Tecnológico concedido à pesquisadora Rozieli B. Silveira durante as entrevistas, no campus 2 do IF Farroupilha, no dia 19 de dezembro de 2016.

${ }^{15} \mathrm{O}$ acolher está relacionado ao sentimento de pertencimento, ou seja, que o estudante se sinta parte desse grupo, que até então é novo para ele. É um espaço para aproximar-se, ouvir, valorizar e acreditar (GUIMARÃES, 2012).

${ }^{16}$ Depoimento do Coordenador de Eixo Tecnológico concedido à pesquisadora Rozieli B. Silveira durante as entrevistas, no campus 1 do IF Farroupilha, no dia 18 de novembro de 2016
} 
Corrêa (2012) no artigo “As relações sociais na escola e a produção da existência do professor" conduz a reflexão sobre a importância das relações sociais para a produção do conhecimento e a preocupação com as metodologias e conteúdos no TP.

Nos recentes encontros com professores tivemos oportunidade de observar como muitos manifestam, de início, uma maior preocupação com os conteúdos curriculares, com a metodologia a ser utilizada na transmissão desses conhecimentos formais e de como desenvolver seu trabalho docente diante das suas reais condições de trabalho na escola. Essa preocupação é tão grande que pode até mesmo contribuir para dificultar a visualização de outros aspectos importantes do trabalho docente, que gostaríamos de destacar. [...] Desde o início gostaríamos de destacar que acreditamos que não são os conhecimentos formais que a escola transmite o fundamento da formação educativa escolar, embora essa crença possa estar presente em muitas análises a respeito da escola e dos processos educativos. Essa formação educativa se dá através do processo de aquisição do conhecimento, por meio das relações sociais e materiais por meio das quais eles são adquiridos (CORRÊA, 2012, p. 130, grifo nosso).

Deste modo, as relações sociais, os vínculos produzidos na escola, mais especificadamente, na sala de aula são relevantes para uma formação humana e social e, por isso, a necessidade de incluir na concepção escolar os processos éticos, políticos, culturais, históricos, por, enfim, tratar-se da educação do humano (CORRÊA, 2012).

Aqui é oportuno salientar que somente a escola não pode ser considerada como solução dos problemas de exclusão social. Esse discurso carrega a ideologia neoliberal da qual a escola é a responsável e, também, a solução para os problemas sociais. Essas relações entre o todo e as partes, entre escola e a sociedade, são dialéticas, pois apresentam contradições e tensões entre indivíduos e classes sociais (CORRÊA, 2012). Como parte desse movimento, a escola pode, a partir da formação humana e social dos sujeitos, propiciar a compreensão dos processos de produção, do qual fazem parte, enquanto classe trabalhadora (ARROYO, 2012).

Essa análise da totalidade implica reconhecer as relações de produção como diretamente relacionadas às relações sociais do Trabalho Pedagógico. Freitas (1995) em Crítica da organização do trabalho pedagógico e da didática retoma essa relação da escola com o capitalismo e o TP

$\mathrm{Na}$ escola capitalista, os alunos encontram-se expropriados do processo de trabalho pedagógico e o produto do trabalho não chega a ser apropriado por boa parte dos mesmos, e ainda que, em alguns casos, fique em seu poder, carece de sentido para eles (FREITAS, 1995, p. 230). 
Para Freitas (1995) essa expropriação se dá pela "repetência, pela evasão e pela sonegação dos conteúdos durante o processo de aprendizagem" (1995, p. 230). Há uma tendência, a da culpabilização ao estudante sobre seu fracasso, como o discurso de um coordenador em uma reunião no Campus 1: "os alunos devem aprender a dar a volta por cima, por que eles não conseguem dar a volta por cima?" (Informação verbal). ${ }^{17}$ Esse discurso aconteceu, quando os membros questionavam sobre a avaliação, reforçando que quando as notas eram negativas no primeiro semestre, influenciavam negativamente para o desânimo e desmotivação do estudante.

Freitas (1995) apresenta sua análise sobre os processos das avaliações e expõe que a avaliação não é apenas um processo de reconhecer aprendizagem e corrigir os rumos da aprendizagem, mas sim é "um conjunto de práticas que legitima a exclusão da classe trabalhadora da escola e está estreitamente articulada com a organização global do trabalho escolar" (1995, p. 254). Ou seja, a prática da avaliação está revestida do autoritarismo escolar. Nesse fragmento, Freitas (1995) sistematiza vários elementos acima problematizados.

Alienado do processo de trabalho pedagógico, individualizado, sujeito a avaliações fragmentadas e longe do trabalho material produtivo, o aluno é condenado a uma situação de ensino sem maior sentido para ele. As resistências do aluno brotam em sala de aula nas mais variadas formas, gerando conflitos que conduzem o professor a fazer o uso de práticas de avaliação, para controlar o comportamento do aluno e assegurar o controle em classe (1995, p. 256).

Os processos dialéticos sobre o Trabalho Pedagógico na escola no sistema de produção capitalista estabelecem uma relação com duas categorias descritas por Freitas (1995). Ele descreve como esse processo se dá na escola e faz uma comparação. Inicialmente, acontece a manutenção da classe dominante em profissões nobres e, em segundo, a eliminação adiada ou manutenção provisória, quando a classe trabalhadora desempenha profissões menos nobres, por conseguinte a manutenção adiada ou exclusão, caracterizada pela evasão e, por último, a eliminação propriamente dita, no sentido de privação da classe trabalhadora do acesso à escola (FREITAS, 1995).

Kuenzer (2002), ao abordar os aspectos dialéticos do TP explica que ainda está presente no TP a lógica da fragmentação e do disciplinamento do mundo capitalista e acrescenta:

\footnotetext{
${ }^{17}$ Depoimento dos integrantes da comissão do PPE concedido à pesquisadora Rozieli B. Silveira durante uma reunião da comissão, no campus 1 do IF Farroupilha, no dia 24 de novembro de 2016.
} 
Ora, se o Trabalho Pedagógico, escolar e não escolar, ocorre nas e através das relações sociais e produtivas, ele não está imune às mesmas determinações. Ou seja, enquanto não for historicamente superada a divisão entre capital e trabalho, o que produz relações sociais e produtivas que têm a finalidade precípua de valorização do capital, não há possibilidade de existência de práticas pedagógicas autônomas; apenas contraditórias, cuja direção depende das opções políticas da escola e dos profissionais da educação no processo de materialização do projeto político-pedagógico (KUENZER, 2002, p. 13).

Esse processo é dialético, as relações sociais no Trabalho Pedagógico apresentam-se em conflito, em distanciamento, fragmentado e alienado. Os processos de responsabilização individual pelo fracasso escolar acabam por produzir vínculos de culpabilização mútua entre os sujeitos, permitindo a possibilidade da reprovação e da evasão. Como se trata de uma realidade concreta há movimentos que buscam resgatar os sentidos de os estudantes estarem na escola. Há discursos que retomam a equivalência e a aprendizagem, e os discursos que retomam o vínculo condicionado às notas, ao comportamento, muitas vezes rebelde, do estudante.

Certamente esses processos contraditórios são resultantes do capitalismo e como Kuenzer (2002) argumenta, está nele também, a possibilidade de superação que se daria pela superação entre capital e trabalho. Assim, é preciso saber como a fragmentação opera no cotidiano escolar, ter clareza como operam esses limites descritos, como a fragmentação, a reprovação, a evasão, o distanciamento, o disciplinamento. Ou seja, a partir da contradição, buscar a superação.

\section{Considerações finais}

Esse artigo, como parte de uma pesquisa de mestrado, surgiu das inquietações de uma das pesquisadoras, enquanto trabalhadora do IF Farroupilha, sobre o contexto real da vida desses sujeitos da escola. É a partir dessas relações humanas que se constitui o Trabalho Pedagógico, como já problematizado anteriormente. A produção do conhecimento dar-se-á pelas relações que se estabelecem entre professores, estudantes, técnico-administrativos e a própria instituição. Prioritariamente o Trabalho Pedagógico acontece entre professor e estudante, porém pode ser desenvolvido por outros sujeitos pertencentes à instituição e que representem o projeto pedagógico institucional (FERREIRA, 2010).

O TP acontece, essencialmente, pelas relações construídas e nesta pesquisa, essas relações são marcadas pelo conflito, pelo distanciamento afetivo, pela fragmentação, pela burocratização. Obviamente, esse movimento contraditório não é o único, outros movimentos, condizentes com a política dos Institutos Federais, evidenciam o TP enquanto práxis, como por exemplo, as ações de acolhimento e os movimentos de ocupação pelos estudantes. 
Assim, as relações no Trabalho Pedagógico ocorrem de duas formas observadas na pesquisa: quando o estudante sente-se acolhido pela instituição, tem garantias sobre a aprendizagem e sua construção como cidadão ou quando as relações no TP estão condizentes com o sistema de produção, selecionando os mais "aptos" e aqueles que não se adéquam aos sistemas de avaliação, de comportamento e de disciplina. Como Freitas (1995) descreve, esse processo vai desde a manutenção provisória para a exclusão, até a eliminação propriamente dita, quando é negado o direito à educação, aos trabalhadores.

As relações no TP podem ser entendidas como movimentos dialéticos, pois reproduzem a realidade, o legado de concepções sobre a Educação Profissional e Tecnológica (EPT), sobre permanência e êxito, os vínculos, a supremacia dos encaminhamentos e a responsabilização pelos fracassos.

Como Kuenzer (2002) sinalizou, os processos contraditórios são resultantes do capitalismo e está nele a possibilidade de superação. Para isso é necessário que compreender como a fragmentação opera no cotidiano escolar, ter clareza como operam esses limites, como: a fragmentação entre Educação e trabalho; a reprovação; a evasão; o distanciamento que se dá pelos encaminhamentos; e a expulsão como forma de disciplinamento. É preciso ter clareza sobre os objetivos dos Institutos Federais e, embora a permanência e o êxito tenham tomado um espaço de destaque na Instituição, após o Acórdão do TCU, se faz necessário refletir sobre as contradições que operam no cotidiano das instituições e nas relações construídas entre os sujeitos que vivenciam o TP.

Assim, que grande parte dos sujeitos da escola sejam tomados pela reflexão sobre suas práticas, sobre as concepções de EPT, de permanência, de êxito e também de ser humano. Que os estudantes da classe trabalhadora tenham acesso e permaneçam em uma escola que ofereça conhecimentos com sentidos e que as relações no Trabalho Pedagógico sejam capazes de compreender o conflito como importante e necessário para que a práxis aconteça, e que de fato vivenciem uma formação como sujeitos do processo educacional.

\section{Referências}

ARROYO, M. Trabalho - Educação e teoria pedagógica. In: FRIGOTTO, G. Educação e crise do trabalho. 11. ed. Petrópolis: Vozes, 2012. p. 138-165.

ARROYO, M. O Direito do trabalhador à educação. In: GOMEZ, C. M.; FRIGOTTO, G.; ARROYO, M.; NOSELLA, P. Trabalho e conhecimento: dilemas na educação do trabalhador. 6. ed. São Paulo: Cortez, 2012. p. 75-90.

BOCK, A. M. B.; GONÇALVES, M. da G. M.; FURTADO, O. (org.). Psicologia Sócio-Histórica: uma perspectiva crítica em psicologia. 6. ed. São Paulo: Cortez, 2015. 
BOCK, A. M. B.; FURTADO, O.; TEIXEIRA, M. de L. T. Psicologias: uma introdução ao estudo de psicologia. 14. ed. São Paulo: Saraiva, 2008.

BRASIL. MEC. SETEC. IFFARROUPILHA. Programa Permanência e Êxito. Farroupilha: Instituto Federal Farroupilha, 2014. Disponível em: http://w2.iffarroupilha.edu.br/site/conteudo.php?cat=168\&sub=6013. Acesso em: 27 abril 2016.

BRASIL. MEC. SETEC. IFFARROUPILHA. Política de Assistência Estudantil. Farroupilha: Instituto Federal Farroupilha, 2012. Disponível em: https://www.iffarroupilha.edu.br/component/k2/attachments/download/1533/6248614b230ee7d18d6d680ef83c43a1. Acesso em: 30 maio 2017.

BRASIL. MEC. SETEC. IFFARROUPILHA. Diagnóstico quantitativo e qualitativo das taxas de evasão, retenção e conclusão. Farroupilha: Instituto Federal Farroupilha, 2016.

BRASIL. Relatório do Tribunal de Contas n. 506/2013. Diário Oficial da União, Brasília, DF, 18 abr. 2013. Disponível em: http:// pesquisa.in.gov.br/imprensa/jsp/visualiza/index.jsp?jornal=1\&pagina=163\&data=18/03/2013. Acesso em: 03 jun. 2016.

CORRÊA, V. As relações sociais na escola e a produção da existência do professor. In: FRIGOTTO, G.; CIAVATTA, M.; RAMOS, M. (org.). Ensino médio integrado: concepções e contradições. 3. ed. São Paulo: Cortez, 2012. p. 128-147.

FERREIRA, L.S. Trabalho Pedagógico. In: OLIVEIRA, D. A. et al. DICIONÁRIO: trabalho, profissão e condição docente. Belo Horizonte: UFMG/ Faculdade de Educação, 2010. CDROM.

FERREIRA, L.S. Trabalho Pedagógico na escola: sujeitos, tempo e conhecimentos. Curitiba: CRV, 2017.

FREITAS, L. C. de. Crítica da organização do trabalho pedagógico e da didática. Campinas, SP: Papirus, 1995.

FRIGOTTO, G. O enfoque da dialética materialista histórica na pesquisa educacional. In: FAZENDA, I. (org.). Metodologia da pesquisa educacional. 12. ed. São Paulo: Cortez, 2010. p.69-90.

FRIZZO, G. F. E.; RIBAS, J. M.; FERREIRA, L. S. A relação trabalho-educação na organização do trabalho pedagógico da escola capitalista. Revista Educação, Santa Maria, v. 38, n. 3, p. 553-564, set./dez. 2013. Disponível em: https://periodicos.ufsm.br/ reveducacao/article/view/8987/pdf. Acesso em: 17 ago. 2017. https://doi.org/10.5902/198464448987

GUIMARAES, S. L. A entrevista de acolhimento e o contrato de trabalho pedagógico como uma possibilidade frente à evasão escolar em um curso superior de tecnologia. 2012. 143 f. Dissertação (Mestrado Acadêmico em Educação) - Universidade Estadual de Campinas, Campinas, 2012. https://doi.org/10.20396/sinteses.v0i7.11567 
KUENZER, A. Z. Exclusão includente e inclusão excludente: a nova forma de dualidade estrutural que objetiva as novas relações entre educação e trabalho. In: LOMBARDI, J. C.; SAVIANI, D.; SANFELICE, J. L. (org.). Capitalismo, trabalho e educação. Campinas, SP: Autores Associados, HISTEDBR, 2002. p. 75-96. https://doi.org/10.20396/rho.v10i37e.8639798

MACHADO, A. M. Avaliação e fracasso: a produção coletiva da queixa escolar. In: AQUINO, J. G. Erro e fracasso escolar: alternativas teóricas e práticas. São Paulo: Semmus, 1997. p.73-90.

MARASCHIN, M. S. Dialética das disputas: trabalho pedagógico a serviço da classe trabalhadora?. 2015.316 f. Tese (Doutorado em Educação) - Universidade Federal de Santa Maria, Santa Maria, 2015. https://doi.org/10.14393/19834071.2015.28847

PARO, V. H. Gestão democrática na escola pública. São Paulo: Ática, 2000.

PATTO, M. H. S. A produção do fracasso escolar: histórias de submissão e rebeldia. 4. ed. São Paulo: Intermeios, 2016.

SAVIANI, D. Pedagogia histórico-crítica: primeiras aproximações. 11. ed. rev. Campinas, SP: Autores Associados, 2011. https:// doi.org/10.5212/praxeduc.v.8i1.0013

Recebido em: 30/4/2018.

Aprovado em: 20/12/2019.

Publicado em: 17/4/2020.

\section{Endereço para correspondência:}

Rozieli Bovolini Silveira

Universidade Federal de Santa Maria

Av. Roraima, 1000, Prédio 13, sala 1118 - Bairro Camobi

97105-900, Santa Maria, RS, Brasil

\section{Autoras:}

Rozieli Bovolini SiLveIRA

Mestre em Educação Profissional e Tecnológica pela Universidade Federal de Santa Maria (UFSM), Santa Maria, RS, Brasil. Técnico-administrativa em Educação na Universidade Federal de Santa Maria (UFSM), Santa Maria, RS, Brasil.

Orcid: https://orcid.org/0000-0001-5923-1354

E-mail: rozielisilveira@gmail.com

Mariglei Severo Maraschin

Doutora em Educação pela Universidade Federal de Santa Maria (UFSM, Santa Maria, RS, Brasil). Professora da Universidade Federal de Santa Maria

(UFSM), Santa Maria, RS, Brasil.

Orcid: https://orcid.org/0000-0002-9705-1896

E-mail: marigleism@hotmail.com 